\title{
GMR
}

\section{Identification of low potassium stress-responsive proteins in tobacco (Nicotiana tabacum) seedling roots using an iTRAQ-based analysis}

\author{
X.L. Ren ${ }^{1 *}$, L.Q. $\mathbf{L i}^{2 *}$, L. Xü ${ }^{2}$, Y.S. Guo ${ }^{1}$ and L.M. $\mathrm{Lu}^{2}$ \\ ${ }^{1}$ Guizhou Academy of Tobacco Science, Longtanba, Guiyang, \\ Guizhou Province, China \\ ${ }^{2}$ Agronomy College, Sichuan Agricultural University, Huimin, \\ Wenjiang, Chengdu, Sichuan Province, China \\ *These authors contributed equally to this study. \\ Corresponding authors: X.L. Ren / L.M. Lu \\ E-mail: renxuel@126.com / louis_luliming@126.com \\ Genet. Mol. Res. 15 (3): gmr.15038573 \\ Received February 19, 2016 \\ Accepted May 4, 2016 \\ Published August 29, 2016 \\ DOI http://dx.doi.org/10.4238/gmr.15038573
}

Copyright (C) 2016 The Authors. This is an open-access article distributed under the terms of the Creative Commons Attribution ShareAlike (CC BY-SA) 4.0 License.

\begin{abstract}
Potassium is one of the three main mineral nutrients, and is vital for leaf growth and the quality of tobacco (Nicotiana tabacum) plants. In recent years, the isobaric tags for relative and absolute quantitation (iTRAQ) method has been one of the most popular techniques for quantitative proteomic analysis. In this study, we used iTRAQ to compare protein abundances in the roots of control and low potassium-treated tobacco seedlings, and found that 108 proteins were differentially expressed between the two treatments. Of these, 34 were upregulated and 74 were downregulated, and 39 (36\%) were in the chloroplasts. Kyoto Encyclopedia of Genes and Genomes pathway enrichment results suggested that metabolic pathways were the dominant pathways (10 upregulated and 14 downregulated proteins).
\end{abstract}

Genetics and Molecular Research 15 (3): gmr.15038573 
Ten proteins involved in the pyruvate metabolism pathway increased their expression levels, and 17 upregulated proteins were enriched in the ribosomes category. To evaluate correlations between protein and gene transcript abundances, the expression patterns of 12 randomly chosen genes were examined. A quantitative real-time polymerase chain reaction revealed that the 12 genes were induced after low potassium treatment for $3,6,12$, and $24 \mathrm{~h}$. Our results demonstrate that low potassium levels affect protein profiles in tobacco roots.

Key words: Potassium; iTRAQ; Root; Quantitative real-time PCR; Tobacco

\section{INTRODUCTION}

Three major mineral nutrients, nitrogen, phosphorus, and potassium, are necessary for plants to live. Potassium deficiency is a key abiotic stress factor when it occurs in the early stages of plant growth (Karam et al., 2009). Although potassium ions $\left(\mathrm{K}^{+}\right)$are fairly abundant in the lithosphere and soils, most of them (90-98\%) are unavailable to plants (Römheld and Kirkby, 2010). Plants uptake potassium mainly through potassium absorption systems located in the cell membrane, which include high-affinity potassium uptake transporters such as the $\mathrm{KUP} / \mathrm{HAK} / \mathrm{KT}$ and HKT families and low-affinity potassium uptake ion channels such as the Shaker and KCO families (Very and Sentenac, 2003). In addition to $\mathrm{K}^{+}$transporters and $\mathrm{K}^{+}$ channels, certain cytoplasmic enzymes in cells play important roles in $\mathrm{K}^{+}$signal transduction, such as transcription factors (i.e., REST; Cheong et al., 2005), calcium signaling (CBL/ CIPK; Xu et al., 2006), and pyruvate kinases (Armengaud et al., 2009). Isobaric tags for relative and absolute quantitation (iTRAQ) is considered one of the most robust methods to perform differential quantitative proteomic analysis (Wilm, 2009). Several studies have demonstrated that iTRAQ is an effective method for examining proteins that are differentially expressed under different stressful physiological conditions. For example, it has been used in a proteomic analysis of grapevine leaves under heat stress conditions (Liu et al., 2014), and to investigate the response of maize to heavy metal (lead) stress (Li et al., 2016). To the best of our knowledge, only a few proteomic studies have been conducted on low potassium levels in plants, and these have been on Arabidopsis (Kang et al., 2004) and ramie (Deng et al., 2014). Tobacco (Nicotiana tabacum) is an important economic crop, and is used as a model plant in gene function research. Lu et al. (2015) conducted a transcriptome analysis of tobacco seedlings in a low potassium treatment; however, mRNA expression levels may not fully reflect the functional proteome. To date, no iTRAQ studies have investigated low potassium stress in tobacco roots. Therefore, this study aimed to understand the molecular mechanism of tobacco responses to low potassium at the protein level.

\section{MATERIAL AND METHODS}

\section{Plant materials and growth conditions}

Tobacco variety ' $\mathrm{K} 326$ ' seeds were surface-sterilized and germinated on moist filter paper in the dark at $28^{\circ} \mathrm{C}$ for 5 days; the germinated seedlings were transferred to a pot filled

Genetics and Molecular Research 15 (3): gmr.15038573 
with vermiculite for 20 days in a greenhouse and watered with a Hoagland nutrient solution that favored growth. The seedlings were hydroponically cultured in a growth chamber for 7 days until the pre-culture. The nutrient solution ( $\mathrm{pH} 5.8$ ) was refreshed every 2 days and consisted of $1.427 \mathrm{mM} \mathrm{NH}_{4} \mathrm{NO}_{3}, 0.323 \mathrm{mM} \mathrm{NaH}_{2} \mathrm{PO}_{4} \cdot 2 \mathrm{H}_{2} \mathrm{O}, 0.512 \mathrm{mM} \mathrm{K}_{2} \mathrm{SO}_{4}, 0.998 \mathrm{mM} \mathrm{CaCl}_{2}, 1.643$ $\mathrm{mM} \mathrm{MgSO} \cdot 7 \mathrm{H}_{2} \mathrm{O}, 9.474 \mu \mathrm{M} \mathrm{MnCl}_{2} \cdot 4 \mathrm{H}_{2} \mathrm{O}, 0.075 \mu \mathrm{M}\left(\mathrm{NH}_{4}\right)_{6} \mathrm{Mo}_{7} \mathrm{O}_{24} \cdot 4 \mathrm{H}_{2} \mathrm{O}, 18.882 \mu \mathrm{M} \mathrm{H}_{3} \mathrm{BO}_{3}$, $0.152 \mu \mathrm{M} \mathrm{ZnSO} \cdot 7 \mathrm{H}_{2} \mathrm{O}, 0.155 \mu \mathrm{M} \mathrm{CuSO} \cdot 5 \mathrm{H}_{2} \mathrm{O}, 0.031 \mathrm{mM} \mathrm{FeSO}_{4} \cdot 7 \mathrm{H}_{2} \mathrm{O}$, and $0.031 \mathrm{mM}$ $\mathrm{Na}_{2}$ EDTA $_{2} \mathrm{H}_{2} \mathrm{O}$. After 7 days, 20 seedlings were transferred to a low-potassium nutrient solution that lacked $\mathrm{K}_{2} \mathrm{SO}_{4}$ for 15 days. The other 20 plants continued to grow in the normal solution for 15 days as controls. After 15 days of treatment, two root samples were collected and immediately frozen in liquid nitrogen for protein extraction. For quantitative real-time polymerase chain reaction (PCR) analysis, seedlings were transferred to a low-potassium nutrient solution for 3, 6, 12 , or $24 \mathrm{~h}$; four root samples were then collected for RNA extraction.

\section{Protein extraction, digestion, and iTRAQ labeling}

Protein extraction was performed using the trichloroacetic acid/acetone method, and protein concentration was measured using a Bio-Rad Protein Assay Kit; the quality of the proteins was assessed by sodium dodecyl sulfate polyacrylamide gel electrophoresis. Two sample proteins in tetraethylammonium bicarbonate were then digested with trypsin at $37^{\circ} \mathrm{C}$ for $24 \mathrm{~h}$ using the filter aided sample prep procedure (Wisniewski et al., 2009). The iTRAQ labeling procedure was performed according to the manufacturer instructions for 8-plex iTRAQ (Applied Biosystems); peptides were labeled with different iTRAQ tags in the group after digestion. The mixture of iTRAQ-labeled samples was pooled and subjected to strong cation exchange fractionation.

\section{Liquid chromatography-mass spectrometry and protein data analysis}

The fractionated samples were analyzed using a Tempo nanoflow multidimensional LC system (AB Sciex, Framingham, MA, USA), and a generation of peak lists was performed using the Proteome Discoverer ${ }^{\mathrm{TM}} 1.3$ software. Protein identification and quantification was performed using the ProteinPilot ${ }^{\mathrm{TM}} 4.2$ software. Protein quantitation was performed at the peptide level by following the procedures described at http://www.matrixscience.com/help/ quant_config_help.html, and proteins with a 1.2-fold or more difference between the two treatments were determined as differentially expressed if the $\mathrm{P}$ value was less than 0.05 . To predict the functions of differentially expressed proteins, we functionally categorized the proteins using WEGO (http://wego.genomics.org.cn/cgi-bin/wego/index.pl). Blast2GO (https://www.blast2go.com/) was used to automatically assign protein descriptions and annotations from homologous sequences in public databases, and the Kyoto Encyclopaedia of Genes and Genomes (KEGG) was used to identify pathways.

\section{RNA extraction and quantitative real-time PCR analysis}

Total RNA was extracted using TRIzol reagent (Invitrogen, USA). To avoid genomic DNA contamination, RNA samples were treated with RNase-Free DNase I (TaKaRa, Japan). The quality of the RNA was assessed using a NanoDrop ${ }^{\mathrm{TM}} 2000$ fluorospectrometer and formaldehyde-denaturing gel electrophoresis. Only high quality RNA was used for cDNA generation. Twelve gene-specific primer pairs were designed using the Premier 5.0 software,

Genetics and Molecular Research 15 (3): gmr.15038573 
based on the gene sequences. The $25-\mu \mathrm{L}$ PCR volume contained $1 \mu \mathrm{L}$ cDNA, $12.5 \mu \mathrm{L} 2 \mathrm{X}$ $\mathrm{SYBR}^{\circledR}$ Green Master Mix, and $10 \mu \mathrm{M}$ forward and reverse primers. Three biological replicates were performed in each experiment, and the tobacco actin gene was used as an internal control. The thermal cycling conditions were as follows: $95^{\circ} \mathrm{C}$ for $10 \mathrm{~s}, 95^{\circ} \mathrm{C}$ for $15 \mathrm{~s}$, and $50^{\circ} \mathrm{C}$ for $1 \mathrm{~min}$ for 40 cycles. Relative gene expression levels were calculated using the $2^{-\Delta \Delta \mathrm{Ct}}$ method.

\section{RESULTS}

\section{Identification of proteins in tobacco roots by iTRAQ}

A total of 108 proteins were detected; 34 were upregulated (Table 1) and 74 were downregulated (Table 2). The subcellular locations of the 34 upregulated proteins were classified into six groups (Figure 1A). The chloroplast contained the most proteins (14) followed by the cytoplasm (6) and the mitochondria (5). The 74 downregulated proteins were classified into eight groups (Figure 1B). Of the 108 proteins characterized, 39 (36\%) were in the chloroplast, $31(29 \%)$ were in the cytoplasm, $11(10 \%)$ were in the mitochondria, and $27(25 \%)$ were in other locations. Therefore, several chloroplast proteins were related to low potassium conditions.

Table 1. Upregulated proteins in control (CK) and low potassium (LK) treatments.

\begin{tabular}{|c|c|c|c|}
\hline Protein description & Ratio (LK/CK) & $\mathrm{P}$ value & Subcellular location \\
\hline Proteinase inhibitor I25 & 1.48 & 0.000925892 & Extracellular \\
\hline Catalase & 1.47 & 0.005239158 & Cytoplasm \\
\hline Cysteine peptidase & 1.45 & 0.035555062 & Cytoplasm \\
\hline Glutamate dehydrogenase & 1.32 & 0.003315416 & Cytoplasm \\
\hline Glycoside hydrolase & 1.4 & 0.017858172 & Chloroplast \\
\hline Transferase & 1.55 & 0.034619945 & Chloroplast \\
\hline Transketolase & 1.39 & 0.002179683 & Mitochondria \\
\hline Serine hydroxymethyltransferase & 1.8 & 0.007888317 & Chloroplast \\
\hline Aldehyde dehydrogenase & 1.59 & 0.001063293 & Cytoplasm \\
\hline FAD-linked oxidase & 1.39 & 0.003256981 & Cytoplasm \\
\hline Thioredoxin & 1.84 & 0.004172483 & Extracellular \\
\hline Mitochondrial inner membrane protein & 1.73 & 0.029562795 & Nucleus \\
\hline Aquaporin & 1.3 & 0.028243711 & Plasma membrane \\
\hline Alpha/beta hydrolase & 1.69 & 0.021869517 & Cytoplasm \\
\hline Thioredoxin & 1.39 & 0.010079405 & Plasma membrane \\
\hline Peroxidase & 1.39 & 0.00966943 & Chloroplast \\
\hline FAD-dependent pyridine nucleotide-disulfide oxidoreductase & 1.51 & $2.06774 \mathrm{E}-07$ & Chloroplast \\
\hline Alpha-L-arabinofuranosidase & 1.44 & 0.008171639 & Chloroplast \\
\hline Germin & 1.39 & 0.014684331 & Chloroplast \\
\hline Lipase & 1.58 & 0.000295718 & Chloroplast \\
\hline Aminotransferase & 1.47 & 0.045682415 & Chloroplast \\
\hline Glycoside hydrolase & 1.31 & 0.000166678 & Plasma membrane \\
\hline Serine hydroxymethyltransferase-dependent transferase & 1.95 & 0.000336658 & Chloroplast \\
\hline Peptidase & 1.34 & 0.000104334 & Chloroplast \\
\hline Lipase & 1.43 & 0.018546761 & Nucleus \\
\hline Mitochondrial inner membrane protein (mitofilin) & 1.49 & 0.015838984 & Mitochondria \\
\hline ABA/WDS induced protein & 1.44 & 0.040803847 & Nucleus \\
\hline Peptidase & 1.33 & 0.023805482 & Mitochondria \\
\hline NAD(P)-binding domain & 1.53 & $2.62585 \mathrm{E}-07$ & Chloroplast \\
\hline Aldehyde dehydrogenase & 1.43 & 0.004508479 & Mitochondria \\
\hline Thiamine thiazole synthase & 1.56 & 0.025023852 & Chloroplast \\
\hline Acid phosphatase & 1.93 & 0.049273957 & Chloroplast \\
\hline Thioredoxin & 1.46 & $1.27575 \mathrm{E}-05$ & Mitochondria \\
\hline Nascent-polypeptide-associated complex (NAC) & 1.34 & 0.008215138 & Nucleus \\
\hline Nascent-polypeptide-associated complex (NAC) & 1.34 & 0.008215138 & Nucleus \\
\hline
\end{tabular}

Genetics and Molecular Research 15 (3): gmr.15038573 
Table 2. Downregulated proteins in control (CK) and low potassium (LK) treatments.

\begin{tabular}{|c|c|c|c|}
\hline Protein description & Ratio (LK/CK) & $\mathrm{P}$ value & Subcellular location \\
\hline Glutathione S-transferase & -0.69 & 0.006970282 & Cytoplasm \\
\hline Remorin & -0.64 & $2.00623 \mathrm{E}-05$ & Cytoplasm \\
\hline Universal stress protein $\mathrm{A}$ & -0.56 & 0.007743617 & Cytoplasm \\
\hline Remorin & -0.67 & 0.000120846 & Mitochondria \\
\hline ATP synthase & -0.75 & 0.034276155 & Chloroplast \\
\hline Glutathione S-transferase & -0.73 & 0.000102796 & Chloroplast \\
\hline Pectinesterase & -0.51 & 0.008505205 & Mitochondria \\
\hline Ribosomal protein S2 & -0.75 & 0.001865552 & Cytoplasm \\
\hline Aspartic peptidase & -0.75 & 0.028553603 & Cytoplasm \\
\hline Caffeate O-methyltransferase (COMT) & -0.74 & $9.50239 \mathrm{E}-06$ & Chloroplast \\
\hline $\mathrm{C} 2$ domain & -0.5 & 0.033742988 & Cytoplasm \\
\hline Uncharacterized conserved protein & -0.6 & 0.009789738 & Cytoplasm \\
\hline Alkaline-phosphatase-like & -0.72 & 0.017865337 & Cytoplasm \\
\hline NAD-dependent epimerase & -0.72 & 0.020324753 & Chloroplast \\
\hline Nucleotide-diphospho-sugar transferases & -0.56 & 0.009296243 & Cytoplasm \\
\hline Plant peroxidase & -0.74 & $1.22252 \mathrm{E}-06$ & Chloroplast \\
\hline Uncharacterized conserved protein & -0.66 & 0.007489299 & Mitochondria \\
\hline Nuclear transport factor 2 & -0.68 & 0.047071053 & Nucleus \\
\hline Ribosomal protein S7 domain & -0.65 & 0.029012599 & Cytoskeleton \\
\hline Tubulin & -0.75 & 0.011953203 & Cytoplasm \\
\hline Translation elongation factor & -0.48 & 0.039396994 & Chloroplast \\
\hline Lipase & -0.59 & 0.00014389 & Vacuole \\
\hline Isopropylmalate dehydrogenase & -0.69 & 0.006990147 & Cytoskeleton \\
\hline Peptidyl-prolyl cis-trans isomerase & -0.74 & 0.000233964 & Chloroplast \\
\hline Thioredoxin & -0.64 & 0.002641561 & Chloroplast \\
\hline Villin & -0.74 & 0.000114972 & Nucleus \\
\hline Uncharacterized conserved protein & -0.42 & 0.048706774 & Cytoplasm \\
\hline Haem peroxidase & -0.67 & 0.002686882 & Chloroplast \\
\hline Glycoside hydrolase & -0.62 & 0.043951616 & Extracellular \\
\hline Ribosomal protein S4/S9 & -0.63 & 0.009605923 & Nucleus \\
\hline Haem peroxidase & -0.64 & 0.005739454 & Chloroplast \\
\hline Globin & -0.6 & 0.006845866 & Chloroplast \\
\hline Peroxidase & -0.64 & 0.002828069 & Extracellular \\
\hline Protein notum & -0.77 & 0.00065519 & Chloroplast \\
\hline Cytochrome & -0.77 & 0.000672261 & Cytoplasm \\
\hline Transposase & -0.67 & 0.045464603 & Cytoplasm \\
\hline Cytochrome & -0.73 & 0.016249339 & Chloroplast \\
\hline START-like domain & -0.54 & 0.015738169 & Cytoplasm \\
\hline Leucine-rich repeat & -0.44 & $9.34995 \mathrm{E}-06$ & Nucleus \\
\hline Vacuolar $\mathrm{H}^{+}$-ATPase & -0.6 & 0.020478224 & Mitochondria \\
\hline Peroxidase & -0.75 & 0.000667813 & Cytoplasm \\
\hline Activator of ATPase & -0.72 & 0.007957409 & Cytoplasm \\
\hline Proteinase inhibitor & -0.68 & 0.034692717 & Vacuole \\
\hline Haem peroxidase & -0.75 & $1.96031 \mathrm{E}-07$ & Extracellular \\
\hline Ribosomal protein & -0.72 & 0.002897013 & Cytoplasm \\
\hline Cyclophilin-type peptidyl-prolyl cis-trans isomerase & -0.77 & 0.000622382 & Chloroplast \\
\hline Alcohol dehydrogenase & -0.71 & 0.018881959 & Cytoplasm \\
\hline Haem peroxidase & -0.63 & 0.003666923 & Chloroplast \\
\hline Isopentenyl-diphosphate delta-isomerase & -0.7 & 0.038869491 & Cytoplasm \\
\hline Plant disease resistance response protein & -0.54 & 0.018780052 & Extracellular \\
\hline Cytochrome P450 & -0.74 & 0.045695798 & Chloroplast \\
\hline Ran binding domain & -0.72 & 0.019149154 & Nucleus \\
\hline Aspartic peptidase & -0.59 & 0.001001565 & Plasma membrane \\
\hline Multicopper oxidase & -0.7 & 0.002282886 & Mitochondria \\
\hline Glycoside hydrolase & -0.68 & 0.000403359 & Chloroplast \\
\hline Thiolase & -0.75 & 0.022940672 & Cytoplasm \\
\hline Nucleotide-diphospho-sugar transferases & -0.62 & 0.008590142 & Cytoplasm \\
\hline Bulb-type lectin domain & -0.76 & 0.006573359 & Chloroplast \\
\hline Plant peroxidase & -0.48 & $5.2889 \mathrm{E}-06$ & Extracellular \\
\hline Polyphenol oxidase & -0.7 & $2.19357 \mathrm{E}-05$ & Chloroplast \\
\hline Barwin-like endoglucanase & -0.65 & 0.022006899 & Chloroplast \\
\hline Glutathione S-transferase & -0.74 & 0.000119419 & Chloroplast \\
\hline Endoglucanase & -0.52 & $5.72916 \mathrm{E}-06$ & Chloroplast \\
\hline RNA recognition motif domain & -0.41 & 0.019582122 & Nucleus \\
\hline Plant disease resistance response protein & -0.66 & $3.64309 \mathrm{E}-05$ & Chloroplast \\
\hline Plant peroxidase & -0.48 & 0.049653979 & Chloroplast \\
\hline Histone $\mathrm{H} 4$ & -0.74 & 0.000126896 & Nucleus \\
\hline Chorismate synthase & -0.75 & 0.033243241 & Chloroplast \\
\hline Acid phosphatase & -0.45 & 0.009447226 & Extracellular \\
\hline Ribosomal protein & -0.65 & 0.012803737 & Mitochondria \\
\hline Rubber elongation factor & -0.56 & 0.027349171 & Cytoplasm \\
\hline 3-hydroxyacyl-CoA dehydrogenase & -0.68 & $7.67137 \mathrm{E}-05$ & Cytoplasm \\
\hline START-like domain & -0.5 & $4.38343 \mathrm{E}-05$ & Cytoplasm \\
\hline Alcohol dehydrogenase & -0.6 & $4.5995 \mathrm{E}-05$ & Cytoplasm \\
\hline
\end{tabular}

Genetics and Molecular Research 15 (3): gmr.15038573 
A

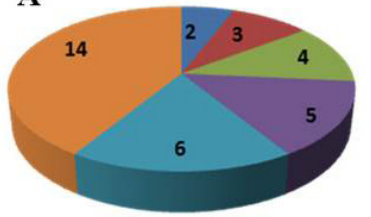

14:Chloroplast

6:Cytoplasm

6: Cytoplasm
5:Mitochondria

4:Nucleus

3:Plastid

2:Extracel

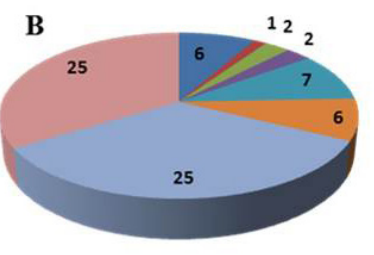

25:Cytoplasm

25:Chloroplast

7:Nucleus

6:Mitochondria

6:Extracel

2:Cytoskeleton

2:Vacuole
1:Plastid

Figure 1. Subcellular localization of upregulated (A) and downregulated (B) proteins.

\section{Functional analysis of the proteins}

To reveal the functions of the differentially expressed proteins after low potassium treatment, they were classified into three large groups and 18 subgroups, depending on their functional annotation. The three large groups were molecular functions, biological processes, and cellular components. Within the molecular functions group, the most populated subgroup was metabolic processes, which accounted for $11.89 \%$. Within the biological processes group, the most populated subgroup was catalytic activity, which accounted for $21.4 \%$, and within the cellular components group, the cell and macromolecular complex subgroup was the most populated subgroup, which accounted for $2.47 \%$. In the catalytic activity subgroup, 20 proteins were upregulated, and 12 and 8 upregulated proteins were included in the metabolic processes and binding groups, respectively. The metabolic processes, catalytic activity, and binding groups were the three largest groups for the downregulated proteins, and included 34, 32, and 30 proteins, respectively (Figure 2).

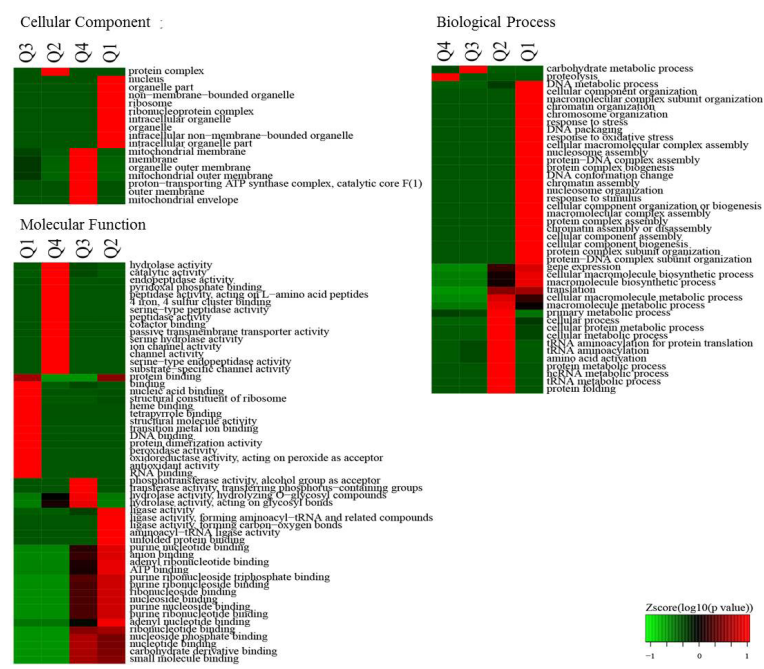

Figure 2. Quantifiable proteins classified by a gene ontology annotation based on cellular compartment, molecular function, and biological process. In each category, the quantifiable proteins were divided into four quantiles based on the cumulative distribution of SILACL/H ratios: Q1, less than 15\%; Q2, 15-50\%; Q3, 50-85\%; Q4, greater than 85\%. 


\section{Pathway and domain analysis of the proteins}

The 108 proteins were assigned to $27 \mathrm{KEGG}$ pathways. The two dominant up-regulated pathways were the metabolic (ko01100) and biosynthesis of secondary metabolites (ko01110) pathways, which contained 10 and 7 proteins, respectively. The two dominant downregulated pathways were the metabolic (ko01100) and ribosome (ko03010) pathways, which contained 14 and 5 proteins, respectively. Protein abundances in the 20 KEGG pathways are presented in Figure 3.

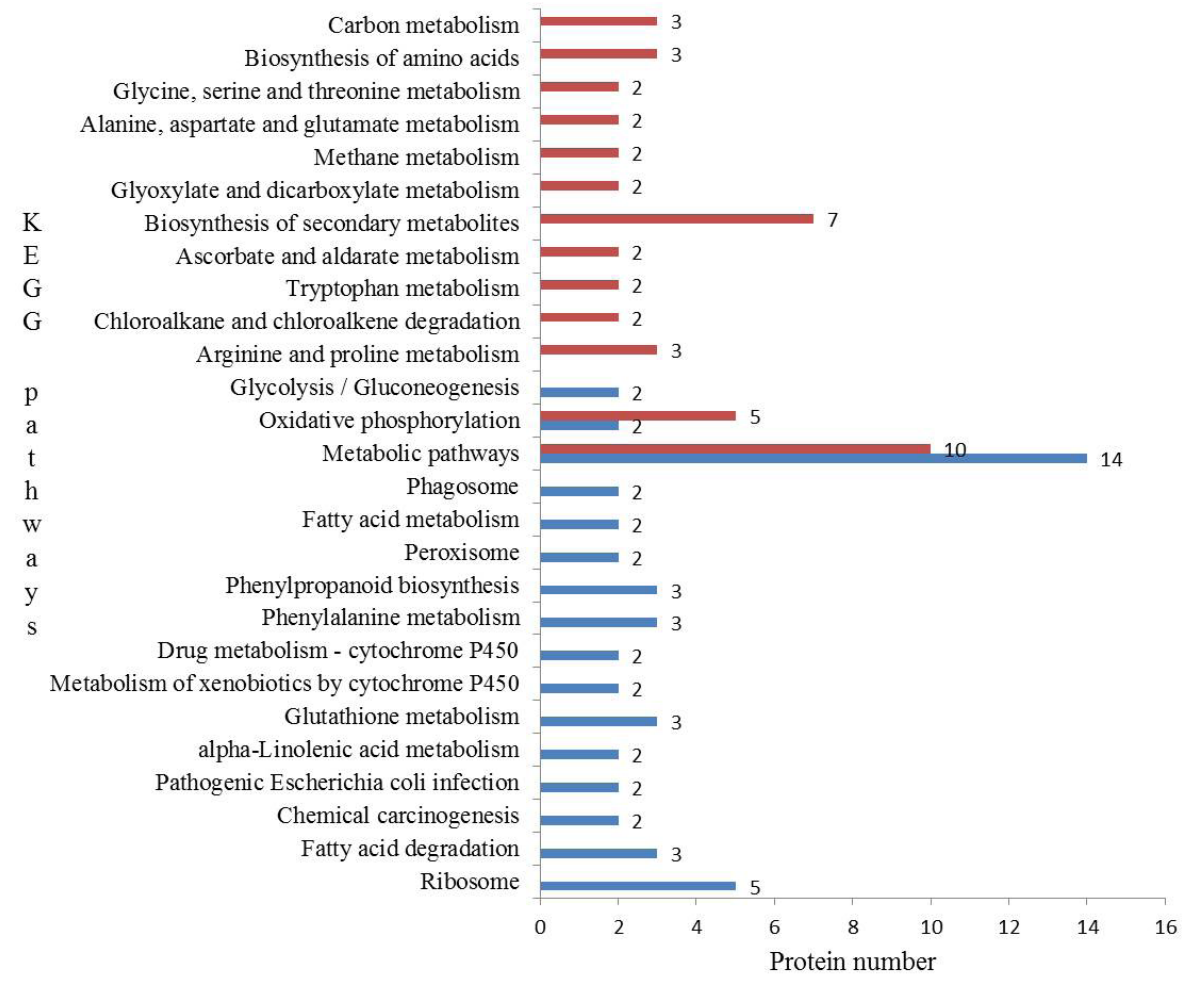

Figure 3. Differentially expressed proteins annotated based on the Kyoto Encyclopedia of Genes and Genomes (KEGG) database. Red bars, upregulated proteins; blue bars, downregulated proteins.

\section{Differentially expressed protein responses to low potassium stress}

The iTRAQ results revealed that 108 proteins were differentially expressed between the control and low potassium treatments, 30 of which were related to reactive oxygen species (ROS), 18 to amino acid metabolism, and 5 to hormone pathways. In addition, 15 proteins were involved in carbon and energy metabolism; of these, serine hydroxymethyltransferase, which is involved in amino acid metabolism, increased its expression 1.95-fold and was the most expressed compared to the controls. The second most expressed protein was acid phosphatase, which increased 1.93-fold and is involved in the decomposition of phospholipids. Thioredoxin (Trx) expression increased 1.84-fold, and occupied third place in terms of highest 
expression level. The RNA recognition motif domain decreased 0.41 -fold, and was the most downregulated protein. An unknown protein was the second most downregulated protein, and decreased 0.42-fold; the leucine-rich repeat protein decreased 0.44-fold and occupied third place. Pyruvate metabolism is related to low potassium levels, because 10 proteins involved in the pyruvate metabolism pathway were upregulated (Figure 4).

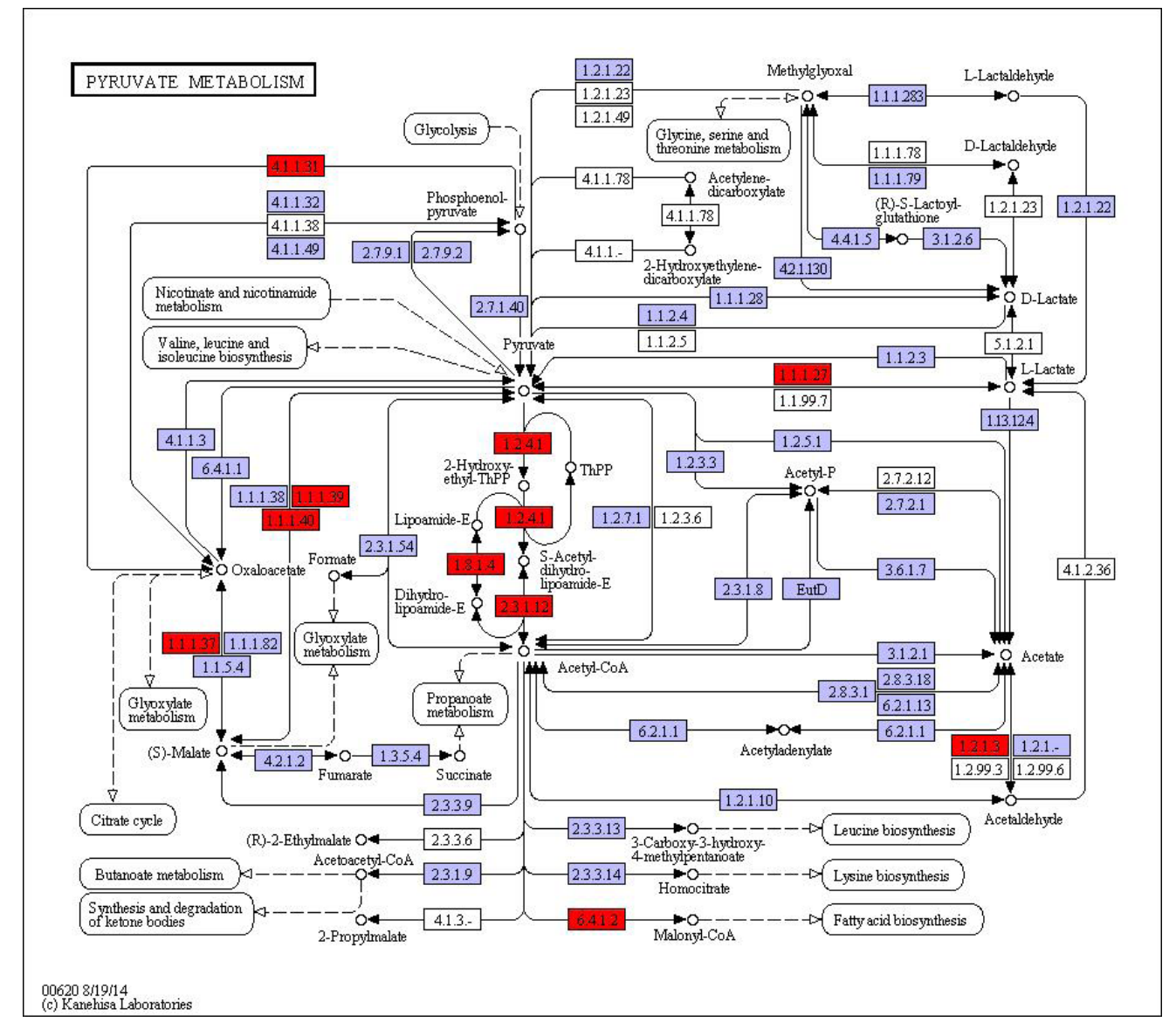

Figure 4. Differentially expressed proteins in control and low potassium treatments in the pyruvate metabolism pathway. Red boxes indicate differentially expressed proteins.

\section{Analysis of important gene expression patterns using quantitative real-time PCR}

To evaluate correlations between the proteins and gene transcript abundance, 12 genes were chosen to examine their expression patterns under the low potassium treatment by quantitative real-time PCR. The assessment included five upregulated proteins and seven downregulated proteins. The primer sequences are listed in Table 3 . The 12 genes were classified into three classes based on the expression results. The first group contained 10 genes, which were all upregulated at the four time points compared to the controls. The second group contained the transketolase protein, which was downregulated at $6 \mathrm{~h}$ but upregulated at 
the three other time points. The third group contained the histone H4 protein, which was only upregulated at $24 \mathrm{~h}$ (Figure 5). Therefore, five upregulated proteins increased their transcript levels at four time points, and seven downregulated proteins were induced at an early stage of the low potassium treatment.

\section{Table 3. Primers used for the quantitative real-time polymerase chain reaction.}

\begin{tabular}{l|l|l}
\hline Gene & Forward primer & Reverse primer \\
\hline Glutamate dehydrogenase NAD(P)+ & TGAGGATAAAGTGAATGCT & GGTCAACCCA GAACATCAAA \\
\hline Shikimate O-hydroxycinnamoyltransferase & TGGTGCACAT ACATTTAAGT & GAAGTCTCTT TTACATGTCC \\
\hline Transketolase & TCGGAATTGACAGATGGGGT & TGGATTCATT TTGGCCGCTC \\
\hline Alpha-N-arabinofuranosidase & CCATCACTTGGCGAAATTCA & AGCAGGATCA ACACTAGTGC \\
\hline THI4: thiamine thiazole synthase & CTGAAATTGA CGGAGCACC & TCCAAAGGTA CACAGTGACA \\
\hline EEF1G: elongation factor & GAGAATGGAT CTGGCACGT & ACTACAACGG TACCACCTCA \\
\hline Small subunit ribosomal protein & TGTCATGGTG GATCTCTTCT & TCTAAAGGAA GCAGGTCTCA \\
\hline Isocitrate dehydrogenase & GCATGCATTG GTGCAGTTG & TTAATGCCTG GAGAGTAACC \\
\hline L-ascorbate peroxidase & CAAGGACATTGTCGCACTCT & ACCTTAAGAT AGGCAGCAAA \\
\hline Large subunit ribosomal protein L12e & AACATCAAGCATAACGGTAA & ATTCCAGAGT TTACTCGTCA \\
\hline Isopentenyl-diphosphate delta-isomerase & TTCACCGTTCGTGAAGTTAA & AGTTATTGGT TTGTAGGGAC \\
\hline Histone H4 & AAGGTGCTGA GGGATAACA & TCCATATAGA GTCCTACCCT
\end{tabular}

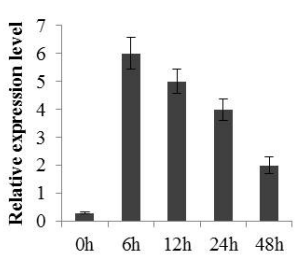

Glutamatedehydrogenase(NA $\mathbf{D}(\mathbf{P})+$
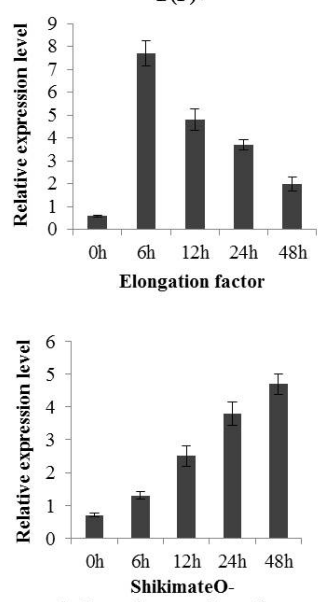

tydroxycinnamovitransferas
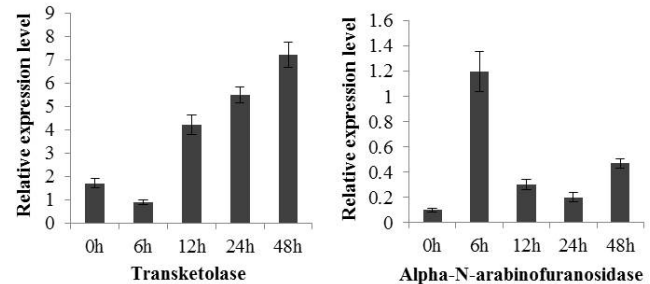

Alpha-N-arabinofuranosidase

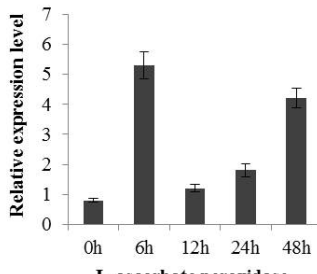

Oh $6 \mathrm{~h} \quad 12 \mathrm{~h} \quad 24 \mathrm{~h} \quad 48 \mathrm{~h}$ Isocitrate dehydrogenase

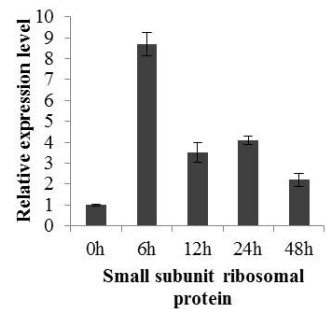
protein

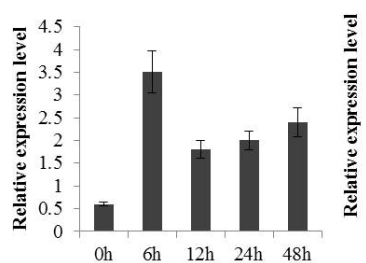

L-ascorbate peroxidase

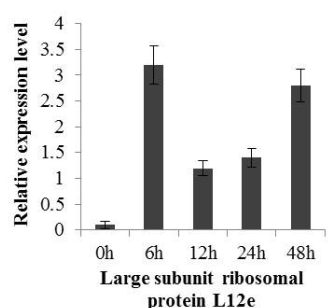
protein L12e
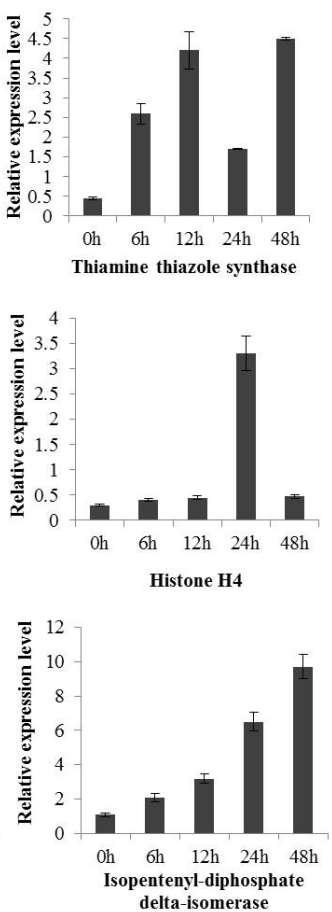

delta-isomerase

Figure 5. Twelve gene expression patterns based on a quantitative real-time polymerase chain reaction. 


\section{DISCUSSION}

\section{ROS scavenging pathways}

A large number of genes that belong to ROS pathways, such as SOD, APX, CAT, POD, GPX, and GST, were found in our study. An excessive accumulation of ROS in cells could induce the peroxidation of membrane lipids and the inactivation of enzymes, among other consequences (Tanou et al., 2009). Proline accumulation is thought to play an important role in plant responses to abiotic stressors. The overexpression of glutamate dehydrogenase from Magnaporthe grisea increases tolerance to dehydration stress in transgenic rice (Zhou et al., 2015). Eleven peroxidases exhibited different expression levels to the controls, and of these, two increased and nine decreased. Kim et al. (2008) reported that the overexpression of sweet potato swpa4 peroxidase in tobacco increases transplant dehydration and $\mathrm{NaCl}$ tolerance. Therefore, peroxidases play key roles under abiotic stress conditions. Two cytochrome b5-like haems decreased; a cytochrome b5-like haem from Arabidopsis acts as a positive regulator that controls lateral root formation (Ikeyama et al., 2010), because in potassium-deficient plants, primary root growth is inhibited (Muday et al., 2012). Cytochrome b5-like haems probably play a role in this process. Four Trxs responded to low potassium levels; three increased their expression levels and one decreased. Trxs are small, ubiquitous oxidoreductases, and a study that investigated the promoter regions of the grape $\operatorname{Trx} h$ gene found that they excite a number of potential cis-acting elements that respond to environmental signals such as salinity, heat, cold, and plant hormones (Haddad and Japelaghi, 2014). Therefore, it is plausible that Trxs are involved in the potassium-signaling pathway in tobacco seedlings.

\section{Metabolism and energy conversion}

In our study, the expression of alcohol dehydrogenase decreased. Alcohol dehydrogenase from soybean roots responds to flood conditions (Komatsu et al., 2011) and is induced by osmotic stress in maize seedlings (Noguchi, 2000), suggesting that this protein actively responds to abiotic stressors. We also found that the expression levels of aldehyde dehydrogenase increased; Xu et al. (2013) reported that the overexpression of aldehyde dehydrogenase from grapevine in Arabidopsis enhanced salt tolerance by protecting plants against oxidative stress. This protein probably has the same function in low potassium conditions. In our study, the expression levels of two lipases increased. The overexpression of the lipase gene CaGLIP1 in Arabidopsis increases drought tolerance (Hong et al., 2008), and lipases from Arabidopsis are involved in ethylene and auxin signaling (Kwon et al., 2009; Lee et al., 2009). Therefore, lipases have a close relationship with low potassium conditions. We found that ATP synthase was downregulated by $0.75-$ fold; however, under phosphorus deficit conditions, ATP protein synthesis increases in Arabidopsis and maize (Wu et al., 2003; Li et al., 2007). This difference might be due to the use of different plant materials. $\mathrm{K}^{+}$deficiency results in increased $\mathrm{H}^{+}$-ATPase activity in tomato (Nieves-Cordones et al., 2008); however, vacuolar $\mathrm{H}^{+}$-ATPase was downregulated by 0.6 -fold in our study. This protein exhibits increased expression under $\mathrm{NaCl}$ and $\mathrm{NaHCO}_{3}$ stress conditions in tomato roots as determined by iTRAQ-based analysis (Gong et al., 2014).

Genetics and Molecular Research 15 (3): gmr.15038573 


\section{Signaling pathways}

In the present study, Hsp90 decreased, but this protein is upregulated after $\mathrm{NaCl}$ and $\mathrm{NaHCO}_{3}$ stress in tomato roots (Gong et al., 2014). Ribosomal proteins are involved in protein synthesis; in this study, five were downregulated under low potassium conditions (S2, S4, S7, S11, and L11), which suggests that protein synthesis decreases when the plant faces a potassium deficiency. L30 decreases its expression levels in soybean under low potassium conditions (Wang et al., 2012), and 21 and 2 ribosomal proteins increased in phosphate- and iron-deficient Arabidopsis roots, respectively (Wang et al., 2013). Aquaporins increased 1.3fold at the transcriptional level in response to low potassium levels (Wang et al., 2012); the involvement of aquaporins in drought and salt tolerance in Arabidopsis and wheat has also been studied (Zhang et al., 2008; Hu et al., 2012).

\section{Stress-related proteins}

Two translation elongation factor eIF5A proteins were downregulated in this study, which is similar to what has been reported at the gene expression level in low potassiumtreated soybean (Wang et al., 2012). We found that the levels of two remorins decreased. An overexpression of remorins in mulberry and Arabidopsis increases salt and dehydration tolerance (Checker and Khurana, 2013). One cyclophilin decreased; OsCYP20-2 increases environmental stress tolerance in tobacco and Arabidopsis (Kim et al., 2012), and OsCYP2-p in transgenic tobacco increases tolerance to salt stress by maintaining ion homeostasis and limiting ROS accumulation (Kumari et al., 2015). Low nitrogen levels induce a cyclophilin protein in tobacco (Yang et al., 2013), which suggests that this type of protein is important in tobacco plants under stress. The expression of a cystatin proteinase inhibitor increased. GsCPI14 (a cystatin proteinase inhibitor) interacting with a calcium/calmodulin-binding receptor (such as the kinase GsCBRLK) increases tolerance to alkali stress in soybean (Sun et al., 2014). In Arabidopsis, two cystatin proteinase inhibitor proteins increase salt, drought, cold, and oxidation tolerance (Zhang et al., 2008). We found that peptidase expression increased; Gong et al. (2015) showed that the expression levels of a calmodulin-binding protein that interacted with calmodulin from Gracilaria lemaneiformis increased under heat shock, because calmodulin has a close relationship with potassium (Xu et al., 2006). Therefore, peptidases play a vital role in the potassium-signaling pathway.

\section{Conflicts of interest}

The authors declare no conflict of interest.

\section{ACKNOWLEDGMENTS}

Research supported by the National Tobacco Corporation of China (\#110201401007JY-07).

\section{REFERENCES}

Armengaud P, Sulpice R, Miller AJ, Stitt M, et al. (2009). Multilevel analysis of primary metabolism provides new insights into the role of potassium nutrition for glycolysis and nitrogen assimilation in Arabidopsis roots. Plant Physiol. 150: 772-785. http://dx.doi.org/10.1104/pp.108.133629

Genetics and Molecular Research 15 (3): gmr.15038573 
Checker VG and Khurana P (2013). Molecular and functional characterization of mulberry EST encoding remorin (MiREM) involved in abiotic stress. Plant Cell Rep. 32: 1729-1741. http://dx.doi.org/10.1007/s00299-013-1483-5

Cheong A, Bingham AJ, Li J, Kumar B, et al. (2005). Downregulated REST transcription factor is a switch enabling critical potassium channel expression and cell proliferation. Mol. Cell. 20: 45-52. http://dx.doi.org/10.1016/j. molcel.2005.08.030

Deng G, Liu LJ, Zhong XY, Lao CY, et al. (2014). Comparative proteome analysis of the response of ramie under N, P and K deficiency. Planta 239: 1175-1186. http://dx.doi.org/10.1007/s00425-014-2040-3

Gong L, Gao MJ, Zang XN, Zhang X, et al. (2015). Peptidase: a novel member of a calmodulin-binding protein of Gracilaria lemaneiformis under heat shock. J. Appl. Phycol. 27: 563-570. http://dx.doi.org/10.1007/s10811-014$\underline{0280-\mathrm{Z}}$

Gong B, Zhang CJ, Li X, Wen D, et al. (2014). Identification of $\mathrm{NaCl}$ and $\mathrm{NaHCO}_{3}$ stress responsive proteins in tomato roots using iTRAQ-based analysis. Biochem. Biophys. Res. Commun. 446: 417-422. http://dx.doi.org/10.1016/j. bbrc.2014.03.005

Haddad R and Japelaghi RH (2014). Abiotic and oxidative stress-dependent regulation of expression of the thioredoxin $h$ multigenic family in grape Vitis vinifera. Biologia 69: 152-162. http://dx.doi.org/10.2478/s11756-013-0309-9

Hong KJ, Choi HW, Hwang IS, Kim DS, et al. (2008). Function of a novel GDSL-type pepper lipase gene, CaGLIP1, in disease susceptibility and abiotic stress tolerance. Planta 227: 539-558. http://dx.doi.org/10.1007/s00425-007-0637-5

Hu W, Yuan QQ, Wang Y, Cai R, et al. (2012). Overexpression of a wheat aquaporin gene, TaAQP8, enhances salt stress tolerance in transgenic tobacco. Plant Cell Physiol. 53: 2127-2141. http://dx.doi.org/10.1093/pcp/pcs154

Ikeyama Y, Tasaka M and Fukaki H (2010). RLF, a cytochrome b(5)-like heme/steroid binding domain protein, controls lateral root formation independently of ARF7/19-mediated auxin signaling in Arabidopsis thaliana. Plant J. 62: 865875. http://dx.doi.org/10.1111/j.1365-313X.2010.04199.x

Kang JG, Pyo YJ, Cho JW and Cho MH (2004). Comparative proteome analysis of differentially expressed proteins induced by $\mathrm{K}^{+}$deficiency in Arabidopsis thaliana. Proteomics 4: 3549-3559. http://dx.doi.org/10.1002/pmic.200400898

Karam F, Rouphael Y, Lahoud R, Breidi J, et al. (2009). Influence of genotypes and potassium application rates on yield and potassium use efficiency of potato. J. Agron. 8: 27-32. http://dx.doi.org/10.3923/ja.2009.27.32

Kim HY, Kim YC, Song WK, Park DS, et al. (2008). Overexpression of sweet potato swpa4 peroxidase results in increased hydrogen peroxide production and enhances stress tolerance in tobacco. Planta 227: 867-881. http://dx.doi. org/10.1007/s00425-007-0663-3

Kim SK, Young YN, Park JC, Joung Y, et al. (2012). The rice thylakoid luminal cyclophilin OsCYP20-2 confers enhanced environmental stress tolerance in tobacco and Arabidopsis. Plant Cell Rep. 31: 417-426. http://dx.doi.org/10.1007/ $\underline{\text { s00299-011-1176-X }}$

Komatsu S, Deschamps T, Hiraga S, Kato M, et al. (2011). Erratum to: Characterization of a novel flooding stressresponsive alcohol dehydrogenase expressed in soybean roots. Plant Mol. Biol. 77: 309-322. http://dx.doi. org/10.1007/s11103-011-9812-y

Kumari S, Joshi R, Singh K, Roy S, et al. (2015). Expression of a cyclophilin OsCyp2-p isolated from a salt-tolerant landrace of rice in tobacco alleviates stress via ion homeostasis and limiting ROS accumulation. Funct. Integr. Genomics 15: 395-412. http://dx.doi.org/10.1007/s10142-014-0429-5

Kwon SJ, Jin HC, Lee S, Nam MH, et al. (2009). GDSL lipase-like 1 regulates systemic resistance associated with ethylene signaling in Arabidopsis. Plant J. 58: 235-245. http://dx.doi.org/10.1111/j.1365-313X.2008.03772.x

Lee DS, Kim BK, Kwon SJ, Jim HC, et al. (2009). Arabidopsis GDSL lipase 2 plays a role in pathogen defense via negative regulation of auxin. Biochem. Biophys. Res. Commun. 379: 1038-1042. http://dx.doi.org/10.1016/j.bbrc.2009.01.006

Li GK, Gao J, Peng H, Shen YO, et al. (2016). Proteomic changes in maize as a response to heavy metal (lead) stress revealed by iTRAQ quantitative proteomics. Genet. Mol. Res. doi: http://dx.doi.org/10.4238/gmr.15017254.

Li K, Xu C, Zhang K, Yang A, et al. (2007). Proteomic analysis of roots growth and metabolic changes under phosphorus deficit in maize (Zea mays L.) plants. Proteomics 7: 1501-1512. http://dx.doi.org/10.1002/pmic.200600960

Liu GT, Ma L, Duan W, Wang BC, et al. (2014). Differential proteomic analysis of grapevine leaves by iTRAQ reveals responses to heat stress and subsequent recovery. BMC Plant Biol. 14: 110-127. http://dx.doi.org/10.1186/1471$\underline{2229-14-110}$

Lu LM, Chen Y, Lu L, Lu YF, et al. (2015). Transcriptome analysis reveals dynamic changes in the gene expression of tobacco seedlings under low potassium stress. J. Genet. 94: 532-541. http://dx.doi.org/10.1007/s12041-015-0532-y

Muday GK, Rahman A and Binder BM (2012). Auxin and ethylene: collaborators or competitors? Trends Plant Sci. 17: 181-195. http://dx.doi.org/10.1016/j.tplants.2012.02.001

Nieves-Cordones M, Miller AJ, Aleman F, Martinez V, et al. (2008). A putative role for the plasma membrane potential in the control of the expression of the gene encoding the tomato high-affinity potassium transporter HAK5. Plant Mol.

Genetics and Molecular Research 15 (3): gmr.15038573 
Biol. 68: 521-532. http://dx.doi.org/10.1007/s11103-008-9388-3

Noguchi HK (2000). Osmotic stress increases alcohol dehydrogenase activity in maize seedlings. Biol. Plantarum 43 : 621-624. http://dx.doi.org/10.1023/A:1002864318871

Römheld V and Kirkby EA (2010). Research on potassium in agriculture: needs and prospects. Plant Soil 335: 155-180. http://dx.doi.org/10.1007/s11104-010-0520-1

Sun XL, Yang SS, Sun MZ, Wang ST, et al. (2014). Novel Glycine soja cysteine proteinase inhibitor GsGPI14, interacting with the calcium/calmodulin-binding receptor-like kinase GsCBLK, regulated plant tolerance to alkali stress. Plant Mol. Biol. 85: 33-84. http://dx.doi.org/10.1007/s11103-013-0167-4

Tanou G, Molassiotis A and Diamantidis G (2009). Induction of reactive oxygen species and necrotic death-like destruction in strawberry leaves by salinity. Environ. Exp. Bot. 65: 270-281. http://dx.doi.org/10.1016/j.envexpbot.2008.09.005

Very AA and Sentenac H (2003). Molecular mechanisms and regulation of $\mathrm{K}^{+}$transport in higher plants. Annu. Rev. Plant Biol. 54: 575-603. http://dx.doi.org/10.1146/annurev.arplant.54.031902.134831

Wang C, Chen HF, Hao QN, Sha HA, et al. (2012). Transcript profile of the response of two soybean genotypes to potassium deficiency. PLoS One 7: e39859.

Wang JY, Lan P, Gao HM, Zheng L, et al. (2013). Expression changes of ribosomal proteins in phosphate and iron deficient Arabidopsis roots predict stress specific alterations in ribosome composition. BMC Genomics 14: 783-797. http://dx.doi.org/10.1186/1471-2164-14-783

Wilm M (2009). Quantitative proteomics in biological research. Proteomics 9: 4590-4605. http://dx.doi.org/10.1002/ pmic.200900299

Wisniewski JR, Zougman A, Nagaraj N and Mann M (2009). Universal sample preparation method for proteome analysis. Nat. Methods 6: 359-362. http://dx.doi.org/10.1038/nmeth.1322

Wu P, Ma L, Hou X, Wang M, et al. (2003). Phosphate starvation triggers distinct alterations of genome expression in Arabidopsis roots and leaves. Plant Physiol. 132: 1260-1271. http://dx.doi.org/10.1104/pp.103.021022

$\mathrm{Xu}$ XZ, Guo RG, Cheng CX, Zhang HJ, et al. (2013). Overexpression of $A L K H 2 B 8$, an aldehyde dehydrogenase gene from grapevine, sustains Arabidopsis growth upon salt stress and protects plants against oxidative stress. Plant Cell Tiss. Organ Cult. 114: 187-196. http://dx.doi.org/10.1007/s11240-013-0314-2

Xu J, Li HD, Chen LQ, Wang Y, et al. (2006). A protein kinase, interacting with two calcineurin B-like proteins, regulates $\mathrm{K}^{+}$transporter AKT1 in Arabidopsis. Cell 125: 1347-1360. http://dx.doi.org/10.1016/j.cell.2006.06.011

Yang HJ, Xu L, Cui H, Zhong BX, et al. (2013). Low nitrogen-induced expression of cyclophilin in Nicotiana tabacum. J. Plant Res. 126: 121-129. http://dx.doi.org/10.1007/s10265-012-0499-1

Zhang XX, Liu SK and Takano T (2008). Two cysteine proteinase inhibitors from Arabidopsis thaliana, AtCYSa and AtCYSb, increasing the salt, drought, oxidation and cold tolerance. Plant Mol. Biol. 68: 131-143. http://dx.doi. org/10.1007/s11103-008-9357-x

Zhou YB, Zhang CS, Lin JZ, Yang YZ, et al. (2015). Over-expression of a glutamate dehydrogenase gene, $M g G D H$, from Magnaporthe grisea confers tolerance to dehydration stress in transgenic rice. Planta 241: 727-740. http://dx.doi. org/10.1007/s00425-014-2214-z

Genetics and Molecular Research 15 (3): gmr.15038573 